\title{
Accuracy of Resolution of ST-Segment Elevation in Electrocardiogram to Determine the Patency of Infarct-Related Artery
}

\author{
Muhammed Kashif Shaikh ${ }^{1}$, Syed Zulfiquar Ali Shah ${ }^{2}$, Chandar Kumar ${ }^{3}$, Munisha Lohano ${ }^{1}$, Abdul \\ Subhan Talpur ${ }^{2}$, Anika Zahoor ${ }^{4}$, Vijay Kumar ${ }^{3}$, Besham Kumar ${ }^{5}$ \\ 1. Interventional Cardiology, Liaquat University of Medical and Health Sciences, Jamshoro, PAK 2. Medicine, Liaquat \\ University of Medical and Health Sciences, Jamshoro, PAK 3. Cardiology, Liaquat University of Medical and Health \\ Sciences, Jamshoro, PAK 4. Internal Medicine, United Medical and Dental College, Karachi, PAK 5. Internal Medicine, \\ Jinnah Postgraduate Medical Centre, Karachi, PAK
}

Corresponding author: Muhammed Kashif Shaikh, drsheikhkashif@yahoo.com

\begin{abstract}
Introduction: There is very limited data comparing the accuracy of ECG to angiography in predicting reperfusion status. In this study, we will determine the accuracy of ECG change i.e. resolution of ST-segment elevation in predicting infarct-related artery (IRA) patency after thrombolysis in patients with ST-segment elevated myocardial infarction (STEMI), in comparison to angiography.
\end{abstract}

Methods: Three hundred and forty-one $(\mathrm{n}=341)$ patients with acute STEMI received streptokinase, a thrombolytic agent within 12 hours of symptoms, and were enrolled in the study via consecutive convenient non-probability sampling. ECG was recorded as soon as the patient arrived in the emergency unit of cardiology. Subsequent ECG was recorded three hours after the administration of streptokinase to look for resolution of ST-segment elevation. ST-segment resolution was classified as greater/equal to $50 \%$ resolved or less than $50 \%$ resolved. Coronary angiography was performed within 24 hours of hospitalization and flow in the IRA was assessed.

Results: The most common site of myocardial infarction (MI) was the anterior wall (50.1\%) and the commonest artery involved was the left anterior descending artery (44.2\%). On ECG, ST-resolution of more than $50 \%$ was found in $242(70.9 \%)$ participants. Thrombolysis in MI (TIMI) grade III flow in angiography was found in 211 (61.8\%) participants. The sensitivity and specificity of ST-resolution to detect TIMI grade III flow was $94.79 \%$ and $67.69 \%$, respectively, while accuracy was $84.46 \%$.

Conclusion: ST-resolution on ECG after streptokinase can predict IRA patency on coronary angiography with moderate to good accuracy. ECG can assist in predicting the impact of streptokinase early in the course of management and give an option of monitoring patient prognosis with a non-invasive test in patients not comfortable with angiography.

Review began 04/09/2021 Review ended 04/12/2021 Published 04/13/2021

() Copyright 2021

Shaikh et al. This is an open access article distributed under the terms of the Creative Commons Attribution License CC-BY 4.0., which permits unrestricted use, distribution, and reproduction in any medium, provided the original author and source are credited.
Categories: Cardiology

Keywords: angiography, ecg, patency, infarct-related artery

\section{Introduction}

Coronary artery disease is a condition in which there is an inadequate supply of blood and oxygen to the myocardium. It results from occlusion of the coronary arteries and results in a demand-supply mismatch of oxygen. It typically involves the formation of plaques in the lumen of coronary arteries that impede the blood flow [1]. Depending on the level of insult, acute coronary syndrome (ACS) presents in the form of unstable angina, non-ST segment elevation myocardial infarction (NSTEMI) or ST-segment elevation myocardial infarction (STEMI) [2]. In Pakistan, STEMI was responsible for $56 \%$ of all myocardial infarction (MI) in a study conducted in 2015 [3].

Management of STEMI recommends reperfusion therapy less than 12 hours after symptom onset [4]. Intravenous thrombolysis is associated with a significant reduction in mortality in acute STEMI [5]. However, in only $60 \%-70 \%$ of patients of acute STEMI, thrombolytic therapy results in grade III flow as per the thrombolysis in MI (TIMI) classification system [6]. Angiography is a gold standard technique to measure the patency of infarct-related artery (IRA) [6]. Non-invasive techniques such as an ECG can also be used to predict the reperfusion status [7]. Ahmed et al. indicated in their pilot study that a $50 \%$ reduction in the sum of ST-segment elevations at four hours after intravenous streptokinase was a useful indicator of the outcome of reperfusion [8]. Hogg et al. reported a high sensitivity of $93 \%$ in patients with more than $50 \%$ resolution of ST-elevation and specificity of 67\% [9]. However, very limited data are available comparing the predictive value of ECG in assessing the patency of IRA after thrombolysis. 


\section{Cureus}

In this study, we will determine the accuracy of ECG change, i.e. resolution of ST-segment elevation in predicting IRA patency after thrombolysis in patients with STEMI, in comparison to angiography. If proven effective, with the help of ECG we shall be able to monitor the prognosis of patients with a less invasive procedure and at a cheaper cost.

\section{Materials And Methods}

This longitudinal study was conducted in the cardiology department of Liaquat University of Medical Health Sciences from August 2020 to January 2021. Ethical approval was taken before the enrollment of patients. Three hundred and forty-one $(n=341)$ new patients with acute STEMI received streptokinase, a thrombolytic agent within 12 hours of symptoms. Patients were enrolled in the study via consecutive convenient non-probability sampling. STEMI was confirmed based on symptoms, electrocardiogram changes (> 1mm ST-segment elevation) and an increase in cardiac enzymes. Details of the study and risk factors associated with the procedure were explained to the patient or their attendant and consent were taken from them.

ECG was recorded as soon as the patient arrived in the emergency unit of cardiology. A detailed history was taken from the patient and/or attendant. Standard treatment, consisting of oxygen therapy, antiplatelet therapy and analgesics, for STEMI was started immediately. A single dose of 1.5 million international unit (IU) streptokinase was infused intravenously over one hour. Subsequent ECG was recorded three hours after the administration of streptokinase to look for resolution of ST-segment elevation. ST-resolution was classified as either greater than $50 \%$ resolved or less than $50 \%$ resolved. Coronary angiography was done within 24 hours of hospitalization and flow in the IRA was assessed. Successful thrombolysis was defined as patients having TIMI grade III flow.

Statistical Package for Social Sciences ${ }^{\circledR}$ software version 23.0 (SPSS; IBM Corp., Armonk, NY, USA) was used for data analysis. For numerical variables, data such as age were expressed as mean \pm standard deviation. Frequencies and percentages were used for categorical variables, such as gender, comorbidities, family history, site of MI, vessel involved, TIMI grade III flow and ST-resolution. An online calculator (MedCalc, Ostend, Belgium) was used to calculate the sensitivity, specificity, positive and negative predictive value for ST-resolution in predicting the success of thrombolysis.

\section{Results}

The mean age of participants in this study was $49 \pm 10$ years. History of hypertension and previous MI was found in $53.3 \%$ and $26.6 \%$ participants, respectively (Table 1 ).

\begin{tabular}{|l|l}
\hline Characteristics & Frequency (P) \\
\hline Age in years (Mean \pm Standard Deviation) & $49 \pm 10$ \\
\hline Male & $200(58.6 \%)$ \\
\hline Female & $141(41.4 \%)$ \\
\hline Known History of Comorbidities & \\
\hline Hypertension & $182(53.3 \%)$ \\
\hline Type 2 Diabetes Mellitus & $162(47.5 \%)$ \\
Hyperlipidemia & $151(44.2 \%)$ \\
\hline Smoker & $112(32.8 \%)$ \\
Hyperuricemia & $52(15.2 \%)$ \\
\hline Past and Family History & \\
\hline Family History of Myocardial Infarction & $21(6.1 \%)$ \\
\hline
\end{tabular}

TABLE 1: Demographics and baseline clinical characteristics of the patients 


\section{Cureus}

anterior descending artery (44.2\%) (Table 2).

\begin{tabular}{|l|l}
\hline Site of Myocardial Infarction & Frequency (Per Involved \\
\hline Anterior Wall Myocardial Infarction & $171(50.1 \%)$ \\
Inferior Wall Myocardial Infarction & $99(29.0 \%)$ \\
\hline Left Wall Myocardial Infarction & $71(20.8 \%)$ \\
\hline Artery Involved & \\
Left Anterior Descending & $151(44.2 \%)$ \\
Right Coronary Artery & $89(26.0 \%)$ \\
Left Circumflex Artery & $81(23.7 \%)$ \\
Left Coronary Artery & $20(5.8 \%)$
\end{tabular}

TABLE 2: Site of myocardial infarction and the artery involved

On ECG, ST resolution of more than 50\% was found in 242 (70.9\%) participants. TIMI grade III flow in angiography was found in 211 (61.8\%) participants. The sensitivity of ST-resolution to detect TIMI grade III flow was $94.79 \%$, specificity was $67.69 \%$ and accuracy was $84.46 \%$ (Table 3).

\begin{tabular}{|c|c|c|c|c|c|c|c|c|}
\hline \multirow{2}{*}{$\begin{array}{l}\text { ECG ST- } \\
\text { Resolution }\end{array}$} & & \multicolumn{2}{|c|}{$\begin{array}{l}\text { TIMI Grade III } \\
\text { Flow }\end{array}$} & \multirow[t]{2}{*}{ Sensitivity \% (Cl) } & \multirow[t]{2}{*}{ Specificity } & \multirow[t]{2}{*}{ PPV } & \multirow[t]{2}{*}{ NPV } & \multirow[t]{2}{*}{ Accuracy } \\
\hline & & Yes & No & & & & & \\
\hline $\begin{array}{l}\text { More than } \\
50 \%\end{array}$ & 242 & 200 & 42 & \multirow{2}{*}{$\begin{array}{l}94.79 \%(90.86 \% \text { to } \\
97.37 \%\end{array}$} & \multirow{2}{*}{$\begin{array}{l}67.69 \%(58.93 \% \text { to } \\
75.63 \%)\end{array}$} & \multirow{2}{*}{$\begin{array}{l}82.64 \%(78.75 \% \text { to } \\
85.95 \%)\end{array}$} & \multirow{2}{*}{$\begin{array}{l}88.89 \%(81.64 \% \text { to } \\
93.50 \%)\end{array}$} & \multirow{2}{*}{$\begin{array}{l}84.46 \%(80.17 \% \text { to } \\
88.14 \%)\end{array}$} \\
\hline $\begin{array}{l}\text { Less than } \\
50 \%\end{array}$ & 99 & 11 & 88 & & & & & \\
\hline
\end{tabular}

\section{TABLE 3: Outcome on the basis of ST-resolution}

ECG: electrocardiogram, TIMI: Thrombolysis in Myocardial Infarction, PPV: positive predictive value, NPV: negative predictive value

\section{Discussion}

The most common comorbidity reported by the participants with acute STEMI was hypertension (53.3\%), followed by type 2 diabetes mellitus (47.5\%). Diabetes is a global problem, and adult diabetes is expected to increase from $2.8 \%$ in 2000 to $4.4 \%$ in 2030 [10]. A positive family history of MI was recorded in $26.6 \%$ of the patients; which is consistent with a study conducted by Saleem et al. [11]. In assessing the most common wall involved in MI, anterior wall MI (50.1\%) topped the list, followed by inferior wall MI (29.0\%). These trends have been supported by a study carried out by Saleem et al. [11]. In terms of artery involvement, the left anterior descending was reported to be affected among $44.2 \%$ of the patients, followed by right coronary artery involvement (26.0\%).

Our study monitored ECG three hours after the administration of streptokinase to measure the extent of the resolution of ST-segment elevation. After the administration of streptokinase, ST-resolution of more than $50 \%$ was observed in $70.9 \%$ of the patients. Effective results have been observed in a similar study conducted at Hayatabad Medical Complex, Peshawar; both partial and complete ST-segment resolution was observed on ECG in 77.11\% patients, three hours after the administration of streptokinase [11]. However, the study also focused on the fact that administration of thrombolytic within 12 hours has shown better results. The difference in results depending on the hourly administration of streptokinase has also been proven by Ch et al. [12]. TIMI grade III flow in angiography was reported in $61.8 \%$ participants. 
showed ST resolution, the study also proved that patients who did not show ST resolution were comparatively at a higher risk of developing complications [13]. It is of keen importance to repeat ECG at regular intervals for better insight into the prognosis as ST resolution improves with time. Anderson et al. assessed the efficacy of thrombolytic therapy on ST resolution in subsequent ECG. ST resolution was reported in $44.2 \%$ and $56.5 \%$ of the patients after one and a half hours and three hours, respectively [14]. The finding of this study is significant, as it provides a non-invasive option in contrast to the coronary angiogram that might not only make the patient anxious but may also be associated with complications [15].

To the best of our knowledge, this is the first study in the local population that compares ECG with angiography to predict the outcome of thrombolysis. Because of the high sensitivity of ECG found in our study, it would give an option to a physician to regularly monitor prognosis without any invasive procedure. However, since our study was conducted in one center, the sample size may be less diverse. Large-scale multicenter studies are needed to confirm finding of our study.

\section{Conclusions}

In patients presenting with acute STEMI, ECG being a simple, readily available, non-invasive and economical modality can be used repetitively as needed for the timely assessment of the quality of reperfusion therapy. ST-resolution on ECG after the administration of streptokinase can predict IRA patency with moderate to good accuracy. Owing to its high sensitivity, ECG can not only assist in predicting the impact of streptokinase early in the course of management but also prove to be a useful tool for risk stratification. Hence, high-risk patients may be promptly referred for an invasive evaluation. Conversely, a low-risk patient can be successfully identified and an immediate adjunctive coronary intervention can safely be avoided; therefore preventing unnecessary intervention and distress to the patient.

\section{Additional Information}

\section{Disclosures}

Human subjects: Consent was obtained or waived by all participants in this study. Liaquat University of Medical and Health Sciences issued approval LUMHS/2020/ERC-11/C. Animal subjects: All authors have confirmed that this study did not involve animal subjects or tissue. Conflicts of interest: In compliance with the ICMJE uniform disclosure form, all authors declare the following: Payment/services info: All authors have declared that no financial support was received from any organization for the submitted work. Financial relationships: All authors have declared that they have no financial relationships at present or within the previous three years with any organizations that might have an interest in the submitted work. Other relationships: All authors have declared that there are no other relationships or activities that could appear to have influenced the submitted work.

\section{References}

1. Dalen JE, Alpert JS, Goldberg RJ, Weinstein RS: The epidemic of the 20(th) century: coronary heart disease . Am J Med. 2014, $127: 807-12.10 .1016 / j . a m j m e d .2014 .04 .015$

2. Nakahara T, Dweck MR, Narula N, Pisapia D, Narula J, Strauss HW: Coronary artery calcification: from mechanism to molecular imaging. JACC Cardiovasc Imaging. 2017, 10:582-93. 10.1016/j.jcmg.2017.03.005

3. Iqbal R, Jahan N, Hanif A: Epidemiology and management cost of myocardial infarction in North Punjab, Pakistan. Iran Red Crescent Med J. 2015, 17:e13776. 10.5812/ircmj.13776v2

4. Windecker S, Hernández-Antolín RA, Stefanini GG, Wijns W, Zamorano JL: Management of ST-elevation myocardial infarction according to European and American guidelines. EuroIntervention. 2014, 10 Suppl T:T23-31. 10.4244/EIJV10STA5

5. Shafique A, Muhammad B: A comparative study of complications in patients of myocardial infarction managed with and without streptokinase. Pak J Cardiol. 2004, 15:51-7.

6. Kiernan TJ, Ting HH, Gersh BJ: Facilitated percutaneous coronary intervention: current concepts, promises, and pitfalls. Eur Heart J. 2007, 28:1545-53. 10.1093/eurheartj/ehm222

7. Schnell GB, Kryski AJ, Mann L, Anderson TJ, Belenkie I: Contrast echocardiography accurately predicts myocardial perfusion before angiography during acute myocardial infarction. Can J Cardiol. 2007, 23:1043-8. 10.1016/s0828-282x(07)70871-1

8. Ahmad I, Ishaq M: ECG and enzymatic indicators of therapeutic success after intravenous streptokinase for acute myocardial infarction--a pilot study. J Pak Med Assoc. 1992, 42:288-90.

9. Hogg KJ, Hornung RS, Howie CA, Hockings N, Dunn FG, Hillis WS: Electrocardiographic prediction of coronary artery patency after thrombolytic treatment in acute myocardial infarction: use of the ST segment as a non-invasive marker. Br Heart J. 1988, 60:275-80. 10.1136/hrt.60.4.275

10. Wild S, Roglic G, Green A, Sicree R, King H: Global prevalence of diabetes: estimates for the year 2000 and projections for 2030. Diabetes Care. 2004, 27:1047-53. 10.2337/diacare.27.5.1047

11. Saleem S, Khan A, Shafiq I: Post thrombolytic resolution of ST elevation in STEMI patients . Pak J Med Sci. 2016, 32:201-5. 10.12669/pjms.321.8974

12. Ch MR, Butt AK: Thrombolysis with intravenous streptokinase dose not alter 72-hours mortality in acute myocardial infarction. Pak Heart J. 2000, 32:1-4.

13. Shuja-ur-Rehman, Sheikh S, Nazeer M: ST segment resolution post MI--a predictor of better outcomes . Pak Med Assoc. 2008, 58:283-6.

14. Anderson RD, White HD, Ohman EM, et al.: Predicting outcome after thrombolysis in acute myocardial infarction according to ST-segment resolution at 90 minutes: a substudy of the GUSTO-III trial. Global Use 


\section{Cureus}

of Strategies To Open occluded coronary arteries. Am Heart J. 2002, 144:81-8. 10.1067/mhj.2002.123319

15. Friedrich GJ, Bonatti J, Dapunt OE: Preliminary experience with minimally invasive coronary-artery bypass surgery combined with coronary angioplasty. N Engl J Med. 1997, 336:1454-5.

10.1056/NEJM199705153362013 